\title{
Evaluating the performance of South African primary care: a cross-sectional descriptive survey
}

\author{
Graham Bresick ${ }^{a}$, Klaus B von Pressentin ${ }^{b}$ (D) and Robert Mash ${ }^{b *}$ \\ ${ }^{a}$ Division of Family Medicine, School of Public Health and Family Medicine, University of Cape Town, Cape Town, South Africa \\ ${ }^{b}$ Division of Family Medicine and Primary Care, Stellenbosch University, Stellenbosch, South Africa \\ *Corresponding author, email: rm@sun.ac.za

Introduction: In 2018 governments reaffirmed their commitment to implementing primary health care (PHC) in the Astana Declaration. South Africa has introduced a number of health reforms to strengthen PHC and enable universal health coverage (UHC). UHC requires access to quality primary care and progress needs to be measured. This study aimed to evaluate the quality of South African primary care using the Primary Care Assessment Tool (PCAT).

Methods: A descriptive cross-sectional survey used data derived from a previous analytical observational study. Data from 413 patients, 136 health workers and 55 managers were analysed from 30 community health centres across four provinces of South Africa. Scores were obtained for 10 key domains and an overall primary care score. Scores were compared in terms of respondents, provinces and monthly headcount.

Results: Patients rated first contact accessibility, ongoing care and community orientation as the poorest performing elements $(<50 \%$ scoring as 'acceptable to good'); first contact utilisation, informational coordination and family-centredness as weaker elements $(<66 \%$ scoring as 'acceptable to good'); and comprehensiveness, coordination, cultural competency and availability of the PHC team as stronger aspects of primary care ( $\geq 66 \%$ or more scoring as 'acceptable or good'). Managers and providers were generally much more positive about the performance of $\mathrm{PHC}$.

Conclusion: Gaps exist between PHC users' experience of care and what PHC staff believe they provide. Priorities to strengthen South African primary care include improving access, informational and relational continuity of care, and ensuring the implementation of community-orientated primary care. The PCAT is a useful tool to measure quality of primary care and progress with UHC.

Keywords: primary health care, primary care, health services evaluation, continuity, accessibility, comprehensiveness, coordination, South Africa

\begin{abstract}
Introduction
Forty years ago the global community articulated a vision for primary health care in the Declaration of Alma Ata as the basis of 'health for all'.' Ten years ago the World Health Organization reiterated that health systems needed primary health care 'now more than ever' and proposed four key reforms related to person-centredness, realising universal coverage, a 'health in all policies' approach, and leadership which is more responsive and accountable to society's needs. ${ }^{2}$ In 2018 countries met again to renew their commitment to primary health care (PHC) at Astana and to make a new declaration. ${ }^{3}$
\end{abstract}

Despite this global commitment to the principles of and need for PHC, actual implementation has not lived up to expectations. This is particularly true in low- and middle-income countries and on the African continent. ${ }^{4} \mathrm{PHC}$ in Africa is often the Cinderella of the healthcare system rather than its foundation. African health systems tend to be under-resourced and hospi-centric with PHC delivered by low-level and poorly trained healthcare workers. ${ }^{4}$ Health care systems are often dependent on foreign aid, which usually targets a few specific diseases such as HIV or malaria. Such an approach reduces PHC to vertical, selective programmes in tackling aspects of the burden of disease rather than promoting delivery of comprehensive PHC that includes health promotion and disease prevention. ${ }^{4}$

South Africa emerged from the Apartheid era with an underdeveloped and fragmented PHC system. ${ }^{5}$ Since the establishment of a fully democratic government in 1994 there has been a policy commitment to improving $\mathrm{PHC}$ for the whole population. This has focused on improving primary care infrastructure and access to care. The health system as a whole remains significantly inequitable with $4.1 \%$ of GDP spent on $84 \%$ of the population who are dependent on the public sector and $4.4 \%$ of GDP on $16 \%$ of the population who have insurance and utilise the private sector. ${ }^{6}$ In the private sector primary care is offered by general practitioners, while in the public sector it is offered largely by clinical nurse practitioners. Despite spending a significant percentage of GDP, the health system is not performing well and faces a quadruple burden of disease characterised by HIV/ AIDS and TB, maternal and child health issues, non-communicable diseases as well as trauma and violence. ${ }^{7}$ Much of this disease burden is preventable.

South Africa has committed itself to a number of reforms designed to improve the quality of $\mathrm{PHC}^{5}$ These include the creation of district clinical specialist teams that focus on maternal and child health as well as the introduction of community health workers in ward-based outreach teams to strengthen community-based health promotion, disease prevention and home-based care. School health services have also been strengthened and a new specialty of family medicine has been recognised with specialists in family medicine placed at district hospitals and health centres. This 'primary health care re-engineering' is part of a broader policy commitment to achieve universal health coverage through the introduction of national health insurance. ${ }^{8}$ National health insurance has the potential to integrate primary care resources from the public and private sectors into one system. 
As South Africa introduces these reforms there is also a need to measure their impact on the quality of primary care. The national Department of Health has launched the Ideal Clinic project, which defines 32 measurable sub-components of quality for primary care clinics. ${ }^{9}$ Clinics in the public sector have been audited nationally and only $9 \%$ were found to be ideal. ${ }^{10}$ This initiative is driving quality improvement, but focuses mainly on structural and not process elements.

There has been growing interest globally in the measurement of primary care systems. A conceptual framework produced by the Primary Health Care Performance Initiative (PHCPI) attempts to define the key components of effective PHC and allocates items to the following categories in a logic model: system, inputs, service delivery, outputs and outcomes. ${ }^{11,12}$ Service delivery has five key sub-categories: population health management, facility and organisational management, access, availability of effective services and high-quality PHC. In the absence of electronic health records and routinely collected data in the African context the Primary Care Assessment Tool (PCAT) is one of the few tools available to measure primary care. ${ }^{13}$ In terms of the PHCPI's framework, the PCAT focuses particularly on the areas of access (financial, geographic, timeliness) and high-quality PHC (first contact accessibility, continuity, comprehensiveness, coordination, and person-centredness).

The original PCAT was developed and validated in the USA to measure the quality of PHC across key dimensions: access, continuity, comprehensiveness, coordination, community orientation, family orientation and cultural competence. ${ }^{14}$ The PCAT has since been adapted for use in a number of countries including low- and middle-income countries in South America and more recently in South Africa and Malawi . ${ }^{13,15,16}$ In the South African adaptation and cross-cultural validation process (ZA PCAT), conducted under the supervision of the original PCAT author, a dimension to measure PHC team availability was added. PHC team functioning has since been added as a second PHC team subdomain. ${ }^{17}$ The first and second ZA PCAT studies measured baseline primary care performance in South Africa's Western Cape Province to identify areas that needed strengthening. ${ }^{16,17}$ It should be noted that although the PCAT focuses on performance of primary care as a facility-based service, the family and community-orientated primary care dimensions include some assessment of the service's connection to the broader population at risk.

No previous studies in South Africa have evaluated these key dimensions on a national scale. This study is also the first of its kind on the African continent. There is interest in many other African countries in adapting and using the PCAT to measure the performance of primary care and to develop interventions. This article re-analyses data that were collected for a cross-sectional analytical observational study that compared the performance of facilities with and without family physicians in seven of the nine provinces in South Africa. ${ }^{19}$ The previous study, however, did not analyse or report on all the available PCAT data to give an overall picture of primary care performance. The aim of this study, therefore, was to use the existing data to report on the performance of primary care in South Africa.

\section{Methods}

\section{Study design}

This was a descriptive cross-sectional study using an existing dataset.

\section{Setting}

South Africa has a population of 56.5 million who live within nine provinces and 52 health districts. This study was located within the public health services that serve $86 \%$ of the population. In the public sector $80 \%$ of primary care consultations are with a clinical nurse practitioner. Primary care is offered in clinics and health centres operating in a district health system. Clinics are smaller facilities that are staffed by nurses and sometimes have a visiting doctor. Health centres are larger facilities that are staffed by a multidisciplinary PHC team consisting of nurses, doctors, pharmacists and allied health workers. Health centres are usually in larger metropolitan areas or rural towns. Some health centres may be open 24 hours per day and include an emergency centre as well as a midwife obstetric unit for low-risk deliveries.

Clinical nurse practitioners typically have one year of additional training to function as medical generalists. Primary care doctors usually have no postgraduate training in family medicine and many are junior doctors completing internship or community service. Family physicians are specialists in family medicine with four years of postgraduate training. Family physicians are scarce $\left(0.03\right.$ per 10,000 population in the public sector $\left.{ }^{20}\right)$, may be employed as the senior clinician at a health centre and often have responsibility for clinical governance within the whole sub-district. If employed at the district hospital they may still perform outreach to the primary care platform.

As mentioned in the introduction a recent policy initiative has been the development of teams of community health workers linked to primary care facilities and responsible for a designated population. They are meant to visit households, identify and respond to health risks, and improve the linkage of the population served to the primary care facility.

\section{Sample size}

The original sample size was calculated to allow a comparison of health centres with and without family physicians. The calculation was based on the diabetes management score and 14 health centres in each arm gave an $80 \%$ power to detect an effect size of $10 \%$ with a $5 \%$ type 1 error. The final sample was 15 health centres in each arm and a total of 30 health centres. This article combines the PCAT data from all 30 health centres to describe $\mathrm{PHC}$ performance.

\section{Sampling strategy}

The seven provinces were selected based on the educational footprint of the six universities that participated in the study. For these provinces a list of health centres was obtained from the national Department of Health. In the original study the list was split into health centres with and without family physicians. Two health centres with family physicians were then randomly selected from each province and matched with two health centres without family physicians. Matching criteria included: same province, rural vs. metropolitan location, annual number of patient visits, 24-hour open access or not, and presence of a midwife obstetric unit. Two additional health centres were selected from the Western Cape to give the total of 30 health centres.

\section{Data-collection tool}

The ZA PCAT, adapted and validated for use in South Africa, consists of 10 dimensions as defined in Table 1. These dimensions are also combined to calculate an overall primary care score. Each dimension contains a number of dimension-specific items (Table 1) to determine performance. The respondent's agreement 
Table 1: Dimensions, items and definitions for the PCAT

\begin{tabular}{|c|c|c|}
\hline Dimension & $\begin{array}{l}\text { Number of items } \\
\text { (AS)* }\end{array}$ & Definition $^{21}$ \\
\hline 1. First contact (access) & 5 & $\begin{array}{l}\text { The provision of primary care services that are accessible when a need for care arises. First contact } \\
\text { refers to the primary care provider being responsible for assisting the client to enter the healthcare } \\
\text { system for each non-referred provision of health care }\end{array}$ \\
\hline 2. First contact (utilisation)\# & 3 & $\begin{array}{l}\text { The utilisation of primary care services when a need for care arises. First contact refers to the primary } \\
\text { care provider being responsible for assisting the client to enter the healthcare system for each non- } \\
\text { referred provision of health care }\end{array}$ \\
\hline 4. Coordination (system) & 10 & $\begin{array}{l}\text { Linking of healthcare events and services. Primary care has the responsibility and obligation to } \\
\text { transfer information to and receive it from other resources that may be involved in the care of a client, } \\
\text { and to develop and implement an appropriate plan for healthcare management and disease } \\
\text { prevention }\end{array}$ \\
\hline $\begin{array}{l}\text { 6. Comprehensiveness } \\
\text { (available) }\end{array}$ & 23 & $\begin{array}{l}\text { Primary care makes available a range of essential personal health services that promote and preserve } \\
\text { health and provide care for illness and disability }\end{array}$ \\
\hline $\begin{array}{l}\text { 7. Comprehensiveness } \\
\text { (provided) }\end{array}$ & 9 & $\begin{array}{l}\text { Primary care offers a range of essential personal health services that promote and preserve health } \\
\text { and provide care for illness and disability }\end{array}$ \\
\hline 8. Family-centredness & 3 & $\begin{array}{l}\text { Care understands the impact of family characteristics on the genesis and prevention of ill health, as } \\
\text { well as the response to both medical and psychosocial interventions. Family-centred primary care } \\
\text { recognises and incorporates knowledge of the family context (resources, risk factors, social factors) } \\
\text { into the planning and delivery of primary care }\end{array}$ \\
\hline 9. Community orientation & 6 & $\begin{array}{l}\text { Care refers to efforts to recognise the primary care needs of a defined population. The effective } \\
\text { delivery of services to individuals and communities is based on an understanding of community } \\
\text { needs and the integration of a population perspective in the provision of health care. Primary care } \\
\text { providers contribute to and participate in community assessment, health surveillance, monitoring, } \\
\text { and evaluation }\end{array}$ \\
\hline 10. Culturally competent & 5 & $\begin{array}{l}\text { Care incorporates cultural references into the provision of primary care. Services are designed to be } \\
\text { acceptable to people in the community, who may be distinguished by common values, language, } \\
\text { heritage, and beliefs about health and disease. The views of these groups should be determined and } \\
\text { incorporated into decisions involving policies, priorities, and plans related to the delivery of } \\
\text { healthcare services }\end{array}$ \\
\hline 11. PHC team available & 6 & $\begin{array}{l}\text { The availability of members of the multidisciplinary primary health care team such as social workers, } \\
\text { therapists or community health workers }\end{array}$ \\
\hline 12. Primary care score & (Total) & $\begin{array}{l}\text { Mean of the scores for the eight subdomains in the four core domains (First Contact-Utilisation; First } \\
\text { Contact-Access; Extent of Affiliation with a Place/Doctor; Ongoing Care; Coordination; Coordination } \\
\text {-Information Systems; Comprehensiveness-Services Available; Comprehensiveness-Services } \\
\text { Provided). }\end{array}$ \\
\hline
\end{tabular}

*Adult User Short (AS) version. Item numbers differ for users, practitioners and managers as determined by their respective roles. \#Only the patient questionnaire includes these questions.

with each item is rated on a four-point Likert scale. All three instruments (questionnaires) comprising the ZA PCAT were used: one for patients (ZA PCAT AS), one for primary care practitioners (ZA PCAT $\mathrm{PE})$, and one for facility managers (ZA PCAT FE).

\section{Data-collection process}

We trained four teams with a total of 16 fieldworkers ( 11 health professionals and five assistants with previous experience in research data collection) to collect data in the seven provinces according to a detailed fieldwork protocol (Supplemental Appendix 4 at http://www.AnnFamMed.org/content/16/1/28/ suppl/DC1). Fieldworkers were interviewed before appointment. Training was facilitated by the lead investigator (KBvP) with the support of the first author (GB) over 2-3 days using the PCAT training manual, and consisted of face-to-face training, role playing and practical evaluation in the field. Each team was led by a health professional and supervised by an academic family physician attached to a participating university. The teams also interacted remotely with the lead investigator (KBvP) via telephone, email, and a communication application (WhatsApp).
At each facility teams collected data from 15 patients who were selected randomly on the data-collection days. All primary care providers (nurses and doctors) as well as managers were invited to complete the appropriate questionnaires. The patient instrument (questionnaire) was available in the three main local languages; respondents chose which translation they preferred and trained fieldworkers administered the instrument. Practitioners' and managers' instruments were self-administered.

Facility-level data were collected between June 2015 and March 2016.

\section{Data analysis}

Data was captured with EpiData version 3.1 (EpiData Software, https://www.epidata.dk/) via a double-entry method and using checks to minimise data entry errors. Data were then imported into the Statistical Package for Social Sciences (SPSS) version 25.0 (IBM Corp, Armonk, NY, USA) for further analysis.

Likert-scale scores for each item were combined to give an overall mean score for each domain. The mean scores for each 
Table 2: Profile of the respondents

\begin{tabular}{|c|c|c|c|c|c|c|c|}
\hline Province & Facilities & Doctors & $\begin{array}{c}\text { Nurse } \\
\text { practitioners }\end{array}$ & $\begin{array}{c}\text { Other healthcare } \\
\text { workers }\end{array}$ & $\begin{array}{c}\text { Total primary care } \\
\text { providers }\end{array}$ & Managers & Patients \\
\hline Gauteng & 9 & 15 & 40 & 17 & 72 & 23 & 142 \\
\hline $\begin{array}{l}\text { KwaZulu- } \\
\text { Natal }\end{array}$ & 5 & 9 & 5 & 0 & 14 & 10 & 73 \\
\hline North West & 5 & 2 & 11 & 1 & 14 & 2 & 44 \\
\hline $\begin{array}{l}\text { Western } \\
\text { Cape }\end{array}$ & 11 & 16 & 6 & 14 & 36 & 20 & 154 \\
\hline Total & 30 & 42 & 62 & 32 & 136 & 55 & 413 \\
\hline
\end{tabular}

domain from patients, providers and managers were then compared using a one-way ANOVA and reported with 95\% confidence intervals and $p$-values.

The mean score for each domain was also categorised into those with a score $\leq$ and $>3$. A mean score of $>3$ indicated agreement that the performance was of a high quality. The frequency and percentage of people in each category were then analysed for each domain. These categorical data for each domain were then compared between patients, providers and managers using Pearson's chi-square test. A $p$-value for the comparison was also reported.

The primary care score was calculated from the mean scores for the individual domains and a final mean score was derived for patients, providers and managers. The relationship of the mean primary care score to location (rural vs. metropolitan) for each type of respondent was analysed using an independent t-test. The relationship of the mean primary care score to province and categorised head-count was analysed using a one-way ANOVA.

\section{Results}

The distribution of sites across the provinces differed from the intended sampling method as some provinces did not employ FPs at CHCs or instead exposed all CHCs to FPs employed at the sub-district level. The final dataset was therefore derived from only four provinces: Gauteng (9 CHCs), KwaZulu-Natal (5 $\mathrm{CHCs})$, North West $(5 \mathrm{CHCs})$ and Western Cape $(11 \mathrm{CHCs})$ as shown in Table 2. Of the $30 \mathrm{CHCs}, 12$ were in metropolitan areas and 18 in rural areas. Overall 419 patients were included in the study with a mean age of 44.7 years (13.6 SD) and a range from 0 years to 80 years; $41.2 \%$ were male and $58.8 \%$ female. In total 136 primary care providers completed the questionnaire of whom $45.6 \%$ were nurse practitioners, $30.9 \%$ doctors and $23.5 \%$ other healthcare workers (e.g. other nurses, physiotherapists, pharmacists). Managers included facility managers $(32.7 \%)$, nurses-in-charge (23.6\%), doctors-in-charge $(7.3 \%)$ and other managers (36.4\%). Other managers included healthcare workers in charge of the pharmacy, human resources or other clinical departments in the health centre.

Table 3 presents a comparison of the mean score for each domain by type of respondent. Managers and primary care providers were significantly more positive than patients regarding first contact access, the availability of comprehensive services, community orientation, team availability and overall primary care score.

Table 4 compares the percentage of respondents rating each domain $>3$ for each type of respondent. Managers and primary care providers differed significantly from patients in the same five areas as in Table 3 . Only $61 \%$ of patients gave an overall satisfactory primary care score. Less than half of the patients were satisfied with first contact access, ongoing care and community orientation of services. Less than $60 \%$ of patients were satisfied with informational coordination and family-centredness. The domains rated highest by patients included cultural competency, teamwork, comprehensiveness and coordination.

The results in Tables 4 are presented graphically in Figure 1. This spider-web diagram highlights that patients and healthcare workers differed most markedly in the areas of first contact access and community orientation.

Table 5 compares the mean primary care scores from different respondent types with location and shows that there were no significant differences.

Table 6 compares the mean primary care scores for different respondents with province and facility workload (monthly headcount of patients utilising the facility). Patients differed

Table 3: Comparison of mean scores between respondents for different primary care domains

\begin{tabular}{|c|c|c|c|c|}
\hline Variable & $\begin{array}{l}\text { Patient mean }(95 \% \mathrm{Cl}) \\
\qquad n=419\end{array}$ & $\begin{array}{l}\text { Manager mean }(95 \% \mathrm{Cl}) \\
n=55\end{array}$ & $\begin{array}{l}\text { Provider mean }(95 \% \mathrm{Cl}) \\
\qquad n=136\end{array}$ & $p$-value \\
\hline First contact access & $2.5(2.4-2.6)$ & $3.3(3.2-3.4)$ & $3.3(3.2-3.4)$ & $<0.001$ \\
\hline Ongoing care & $2.9(2.9-3.0)$ & $2.9(2.8-3.0)$ & $3.0(2.9-3.1)$ & 0.337 \\
\hline Coordination & $3.3(3.1-3.4)$ & $3.2(3.1-3.3)$ & $3.3(3.2-3.4)$ & 0.549 \\
\hline Coordination (info) & $3.3(3.2-3.3)$ & $3.5(3.3-3.7)$ & $3.3(3.2-3.5)$ & 0.056 \\
\hline Comprehensiveness (available) & $3.2(3.2-3.3)$ & $3.6(3.5-3.6)$ & $3.6(3.5-3.7)$ & $<0.001$ \\
\hline Comprehensiveness (provided) & $3.2(3.2-3.3)$ & $3.2(3.0-3.3)$ & $3.3(3.2-3.5)$ & 0.365 \\
\hline Family-centredness & $3.2(3.1-3.2)$ & $3.2(3.0-3.3)$ & $3.4(3.2-3.6)$ & 0.023 \\
\hline Community orientation & $2.7(2.7-2.8)$ & $3.6(3.4-3.7)$ & $3.5(3.4-3.7)$ & $<0.001$ \\
\hline Culturally competent & $3.4(3.3-3.5)$ & $3.3(3.2-3.5)$ & $3.4(3.3-3.6)$ & 0.579 \\
\hline Teamwork & $3.4(3.3-3.5)$ & $3.9(3.8-4.1)$ & $3.9(3.8-3.9)$ & $<0.001$ \\
\hline Primary care score & $3.1(3.1-3.1)$ & $3.4(3.3-3.5)$ & $3.4(3.4-3.5)$ & $<0.001$ \\
\hline
\end{tabular}


Table 4: Comparison of mean facility scores for provinces and headcounts by respondent categories

\begin{tabular}{|c|c|c|c|c|c|}
\hline Variable & $\begin{array}{c}\text { Gauteng } \\
11 \mathrm{CHCs} \\
\text { Mean }(95 \% \mathrm{Cl})\end{array}$ & $\begin{array}{l}\text { KwaZulu-Natal } \\
5 \text { CHCs } \\
\text { Mean }(95 \% \mathrm{Cl})\end{array}$ & $\begin{array}{c}\text { North West } \\
3 \mathrm{CHCs} \\
\text { Mean }(95 \% \mathrm{Cl})\end{array}$ & $\begin{array}{c}\text { Western Cape } \\
11 \mathrm{CHCs} \\
\text { Mean }(95 \% \mathrm{Cl})\end{array}$ & $p$-value \\
\hline Patients primary care score & $2.8(2.7-3.0)$ & $3.6(3.3-3.9)$ & $3.1(2.7-3.5)$ & $3.1(3.0-3.2)$ & $<0.001$ \\
\hline Provider primary care score & $3.6(3.4-3.8)$ & $3.4(3.0-3.7)$ & $3.4(3.3-3.5)$ & $3.3(3.1-3.5)$ & 0.088 \\
\hline \multirow[t]{2}{*}{ Manager primary care score } & $3.6(3.4-3.8)$ & $3.5(3.2-3.7)$ & $3.3(2.9-3.8)$ & $3.3(3.1-3.5)$ & 0.057 \\
\hline & $\begin{array}{c}\text { Headcount } \\
0-100000 \\
8 \mathrm{CHCs}\end{array}$ & $\begin{array}{c}\text { Headcount } \\
100001-200000 \\
11 \mathrm{CHCs}\end{array}$ & $\begin{array}{c}\text { Headcount } \\
200001-300,000 \\
5 \text { CHCs }\end{array}$ & $\begin{array}{c}\text { Headcount } \\
>300000 \\
6 \mathrm{CHCs}\end{array}$ & $p$-value \\
\hline \multicolumn{6}{|l|}{ Patients } \\
\hline Patients primary care score & $2.9(2.7-3.2)$ & $2.9(2.8-3.1)$ & $3.4(2.9-3.8)$ & $3.3(3.0-3.7)$ & 0.007 \\
\hline First contact access & $2.2(1.4-3.0)$ & $1.9(1.5-2.4)$ & $3.1(2.1-4.0)$ & $3.5(2.9-4.0)$ & 0.001 \\
\hline First contact utilisation & $3.4(3.1-3.8)$ & $3.2(3.0-3.3)$ & $3.4(2.6-4.1)$ & $3.4(2.9-3.8)$ & 0.585 \\
\hline Ongoing care & $2.9(2.5-3.2)$ & $2.9(2.7-3.1)$ & $3.0(2.6-3.4)$ & $2.9(2.6-3.3)$ & 0.865 \\
\hline Coordination & $3.1(2.8-3.5)$ & $3.4(3.0-3.7)$ & $3.3(2.5-4.2)$ & $3.2(2.5-3.8)$ & 0.713 \\
\hline Coordination (info) & $3.2(2.8-3.6)$ & $3.2(2.9-3.5)$ & $3.4(2.8-4.0)$ & $3.5(3.0-3.9)$ & 0.626 \\
\hline Comprehensiveness (availability) & $2.9(2.6-3.3)$ & $3.3(3.0-3.6)$ & $3.4(3.1-3.8)$ & $3.4(3.0-3.8)$ & 0.128 \\
\hline Comprehensiveness (provided) & $2.9(2.4-3.5)$ & $3.1(2.7-3.6)$ & $3.7(3.4-4.0)$ & $3.4(3.1-3.8)$ & 0.096 \\
\hline \multicolumn{6}{|l|}{ Providers and managers } \\
\hline Provider primary care score & $3.5(3.3-3.6)$ & $3.4(3.2-3.7)$ & $3.6(3.1-4.0)$ & $3.3(3.0-3.6)$ & 0.456 \\
\hline Manager primary care score & $3.5(3.2-3.8)$ & $3.4(3.2-3.7)$ & $3.4(3.3-3.6)$ & $3.4(3.1-3.6)$ & 0.850 \\
\hline
\end{tabular}

significantly between provinces in their scores, while managers and primary care providers did not, although the dataset was underpowered for this comparison. Patients rated KwaZuluNatal highest and Gauteng lowest. Patients also differed significantly in their scores related to facility workload, while managers and primary care providers did not. Patients were more satisfied with facilities that had a higher workload and this appeared largely due to differences in first contact access.

\section{Discussion}

Patients rated first contact accessibility, ongoing care and community orientation as the poorest performing elements of primary care ( $<50 \%$ scoring as 'acceptable to good'). Managers and providers agreed with them in terms of ongoing care, but they were much more optimistic regarding performance on accessibility and community orientation, consistent with findings of PCAT studies in the Western Cape province. ${ }^{16,17}$

Patients rated the overall primary care score, first contact utilisation, informational coordination and family-centredness as weaker aspects of primary care $(<66 \%$ scoring as 'acceptable to good'). Managers and providers agreed with them in terms of family-centredness, but again were significantly more positive regarding the primary care score and informational continuity.

Patients rated comprehensiveness, coordination, cultural competency and the availability of the PHC team as reasonably strong aspects of primary care $(>=66 \%$ or more scoring as 'acceptable or good'). Managers and providers agreed with them but were also much more positive about the comprehensiveness of services and availability of PHC team members.

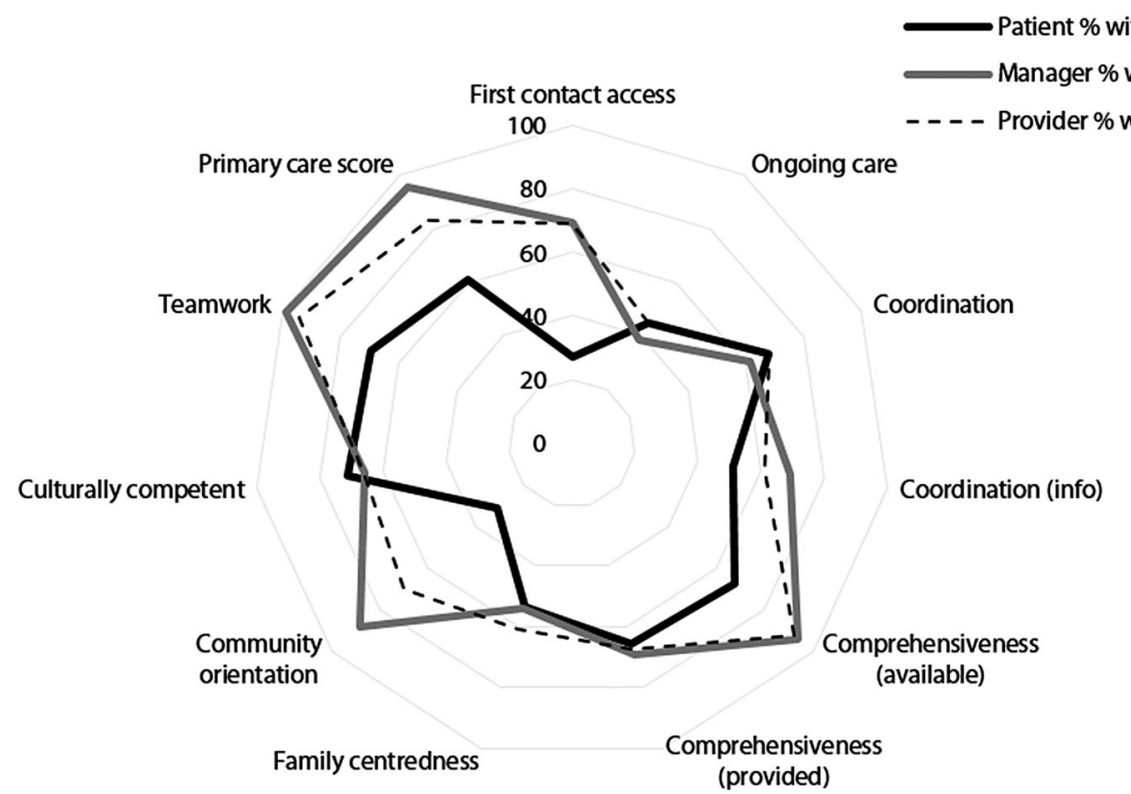

Figure 1: Radar chart of $\%$ of scores $>=3$ between respondent groups for different primary care domains. 
Table 5: Comparison of $\%$ of scores $>=3$ between respondent groups for different primary care domains

\begin{tabular}{|c|c|c|c|c|}
\hline Variable & $\begin{array}{c}\text { Patient } \\
\% \text { with score } 3 \text { or more }\end{array}$ & $\begin{array}{c}\text { Manager } \\
\% \text { with score } 3 \text { or more }\end{array}$ & $\begin{array}{c}\text { Provider } \\
\% \text { with score } 3 \text { or more }\end{array}$ & $p$-value \\
\hline First contact utilisation & 50.4 & - & - & - \\
\hline First contact access & 27.0 & 69.4 & 69.1 & $<0.001$ \\
\hline Ongoing care & 44.6 & 38.8 & 44.4 & 0.607 \\
\hline Coordination & 67.8 & 61.2 & 67.9 & 0.522 \\
\hline Coordination (info) & 51.1 & 69.4 & 61.1 & 0.002 \\
\hline Comprehensiveness (available) & 67.3 & 94.1 & 92.0 & $<0.001$ \\
\hline Comprehensiveness (provided) & 65.6 & 69.4 & 67.3 & 0.775 \\
\hline Family-centredness & 53.5 & 54.1 & 61.1 & 0.243 \\
\hline Community orientation & 31.5 & 88.2 & 69.8 & $<0.001$ \\
\hline Culturally competent & 71.1 & 65.9 & 66.0 & 0.383 \\
\hline Teamwork & 69.5 & 98.8 & 94.4 & $<0.001$ \\
\hline Primary care score & 60.8 & 95.3 & 83.3 & $<0.001$ \\
\hline
\end{tabular}

Despite the focus on improving infrastructure, patients remain dissatisfied with accessibility and only $50 \%$ use their primary care service as first contact. Key issues addressed in the PCAT items that might explain this include the poor availability of primary care services after hours, at weekends and on public holidays. During these times patients are often forced to attend referral hospitals or pay for private health care. This leads to fragmentation of care as well as significant cost to users. Large facilities are more likely to be open 24 hours per day where after-hours services are for emergency care. This may explain why patients scored facilities with a greater headcount higher. However, comprehensive care may not be possible or appropriate in emergency care rooms. The PCAT does not distinguish between access to comprehensive care for common primary care conditions and access to emergency primary care. Accommodating access in terms of the time between entering a facility and seeing a practitioner may also be a factor. In addition, most health centres do not provide telephone access for support or advice when needed. The optimistic scores of providers and managers relative to that of users indicated a significant discrepancy here. The users' experience indicates that timely access is not adequately accommodated in the organisation and delivery of primary care. This highlights a gap in user demand for services and actual supply of health services.

In South Africa patients are not required to register with a specific facility or practitioner (as opposed to high-income country settings) and this enables them to choose a service based on cost, geographic access, accommodation of access or acceptability. Many families choose to consult traditional healers. ${ }^{22}$ Emergency departments at referral hospitals also complain of the large number of primary care patients seeking care and may not be well suited to offer comprehensive or personcentred care. ${ }^{23}$ South Africa is moving towards a national health insurance scheme that will require patients to be registered with a specific facility. ${ }^{8}$
Continuity of care (ongoing care) with the same provider or team is arguably the relational foundation needed to give effect to the other primary care dimensions and is linked to better outcomes. ${ }^{24,25}$ This is particularly important for the success of integrated chronic care for communicable (e.g. HIV and TB) and non-communicable (e.g. diabetes and hypertension) conditions. The findings suggest little real relationship with known and trusted providers and that the SA PHC system does not facilitate seeing the same person or team. This is compounded by poor informational continuity, with most medical records still paper based and not electronic, and the fact that in South Africa PHC reform has focused more on comprehensiveness than continuity. Given the significant body of evidence in favour of continuity of care, ${ }^{24,26,27}$ factors that undermine the realisation of continuity should be addressed more aggressively.

Community-orientated primary care (COPC) is an important policy direction for the Department of Health with the creation of ward-based outreach teams nationally. ${ }^{28}$ The findings suggest that patients were not yet convinced that COPC was a reality, while managers and providers differed significantly. Data were collected in the early days of policy implementation and it is possible that patients' views may have changed. Managers and providers may not have fully understood the principles of COPC and the implications of being community orientated. COPC as a broad approach has been shown to have nine core principles: serving a defined community, involving a multidisciplinary team, being comprehensive, evaluating the community's health needs and resources, community participation, prioritising health needs and planning interventions, using evidence and data, integrating care around users in a person-centred approach, and improving health equity. ${ }^{29}$

Patients rated the comprehensiveness of services much lower than managers or providers. This has been noted elsewhere ${ }^{17}$ and may reflect a lack of patient awareness of services that are

Table 6: Comparison of mean primary care scores for rural and urban locations by respondent

\begin{tabular}{lcccc}
\hline Variable & $\begin{array}{c}\text { Rural } \\
(\boldsymbol{n}=\mathbf{1 2}) \\
\text { Mean }\end{array}$ & $\begin{array}{c}\text { Metro } \\
(\boldsymbol{n}=\mathbf{1 8}) \\
\text { Mean }\end{array}$ & Mean difference (95\% Cl) & $0.097(0.124$ to -0.157$)$ \\
\hline Patients primary care score & 3.1 & 3.0 & $-0.037(0.111$ to -0.264$)$ & 0.442 \\
Provider primary care score & 3.4 & 3.4 & $-0.093(0.107$ to -0.314$)$ & 0.744 \\
Manager primary care score & 3.4 & 3.5 & & 0.395 \\
\hline
\end{tabular}


actually available; and/or that services that are theoretically available are not fully capacitated to meet demand. There may also be a need to improve provider awareness to reduce missed opportunities for health promotion and disease prevention. ${ }^{17}$

In comparison, patients in the first ZA PCAT study ${ }^{18}$ in the Western Cape rated performance on access, community orientation and comprehensiveness of services provided lowest; and coordination of information, cultural competence and teamwork highest. Overall PHC performance (total primary care score) was rated as acceptable to good by $50.2 \%$ of users compared with $82.8 \%$ of the managers and $88.0 \%$ of the practitioners. This illustrates that there may be significant differences in performance between provinces in different parts of the health system and a need for evaluation at different levels of the health system.

A strength of the PCAT is that it enables primary care performance to be measured from the perspectives of users (patients), providers (practitioners) and managers and to compare these. Only patients considered regular users are surveyed. Patients rate performance based on their experience of care over the duration of their association with the facility, minimising the influence of factors operating on the day of the survey. The PCAT measures PHC performance on elements in the service delivery domain of the PHCPI framework, while the Ideal Clinic process focuses more on the systems and input domains. Within service delivery PCAT particularly measures the components of access and quality PHC criteria. Universal health coverage requires not only access to primary care, but also an acceptable quality of primary care. PCAT measures both these elements and is therefore a useful tool to evaluate the progress of interventions to improve PHC. In the South African context it complements the Ideal Clinic norms and standards.

Only four of the possible seven provinces were included in the survey and only 30 health centres were included in the analysis. The survey also excluded clinics, and sampling was based on the needs of an observational study designed to compare facilities with and without family physicians. It is difficult therefore to generalise the findings to primary care as a whole in South Africa. The study does, however, show the value of evaluating the core dimensions using the PCAT and it is likely that key findings point towards real issues that need to be addressed. A more robust survey of primary care should be planned to confirm and follow up on key findings. The PCAT manual requires responses from patients who have attended the facility over time and therefore excludes patients who are no longer utilising the facility and who may be more dissatisfied.

Key recommendations that flow from the findings and that are supported by the literature on primary care include:

- Improve access to primary care after-hours, at weekends and on public holidays.

- Improve the accommodation of timely access to care during normal working hours.

- Focus on service design that fosters informational and relational continuity of care and not just comprehensiveness of care.

- Improve the awareness of community members on the range of services available.

- Improve the implementation of COPC and the understanding of healthcare workers and managers on what this entails.
- Encourage dialogue between users, providers and managers to narrow the differences between respective assessments of PHC performance and foster collaboration.

\section{Conclusion}

This survey identified gaps between the user's experience of PHC and what PHC practitioners and managers believe is being provided-a finding that indicates a gap between user demand for services and provider/manager supply. Primary care facilities surveyed need to improve access to primary care, ongoing care in terms of informational and relational continuity, awareness of the services available to patients, implementation of COPC and the understanding of what this means for managers and healthcare workers. The strongest aspects of primary care were comprehensiveness, coordination, cultural competency and the availability of the PHC team.

Disclosure statement - No potential conflict of interest was reported by the authors.

\section{ORCID}

Klaus B von Pressentin (D) http://orcid.org/0000-0001-5965-9721

\section{References}

1. Declaration of Alma-Ata. [cited 2018 Oct 20] http://www.who.int/ publications/almaata_declaration_en.pdf.

2. Organisation WH. World health report - primary health care: Now more than ever. Geneva: World Health Organisation; 2008.

3. World Health Organization. Astana Declaration on Primary Health Care. (2018). [cited 2018 Dec 18] https://www.who.int/primaryhealth/conference-phc/declaration.

4. Mash R, Howe A, Olayemi O, et al. Reflections on family medicine and primary healthcare in sub-Saharan Africa. BMJ Glob Heal. 2018;3: e000662.

5. Matsoso M, Fryatt R, Andrews G. The South African health reforms, 20092014: Moving towards Universal Coverage. Cape Town: Juta, 2015 [cited 2018 Dec 18] https://scholar.google.co.za/scholar?hl=en\&as $\mathrm{sdt}=0 \% 2 \mathrm{C} 5 \mathrm{q}$ =South-African-Health-Reforms-2009-2014\&btnG=.

6. UNICEF. Health Budget South Africa 2017/2018. Pretoria. 2017. [cited 2018 Dec 18] https://www.unicef.org/esaro/UNICEF_South_Africa_2017_-_Health_Budget_Brief.pdf.

7. Bradshaw $D$, Norman $R$, Schneider M. A clarion call for action based on refined DALY estimates for South Africa. South African Med J. 2007;97:438-440.

8. Matsoso MP, Fryatt B. National health insurance: The first 18 months In: Padarath A, R. E, ed. South African health review 2012/13. Cape Town: Health systems trust 2013: 21-33.

9. Health SSA response to HIV and Ideal Clinic project. 2015. http:// www.sarrahsouthafrica.org/HOMESUPPORTFORHIVANDHEAL TH/EQUALACCESSTOHIVANDHEALTHSERVICES/NATIONALHEALTHIN SURANCE/IDEALCLINICSINITIATIVE.aspx.

10. Hunter J, Chandran T, Asmall S, et al. The Ideal Clinic in South Africa: progress and challenges in implementation. In: Padarath A, Barron P editor. South African health Review, 20th edn Cape Town: Health System trust; 2017. p. 111-124.

11. Primary Health Care Performance Initiative. [cited 2018 Apr 18] https://phcperformanceinitiative.org/.

12. VEILLARD J, COWLING K, BITTON A, et al. Better measurement for performance improvement in Low- and middle-income countries: The primary health care performance initiative (PHCPI) experience of conceptual framework development and Indicator Selection. Milbank Q. 2017;95:836-883.

13. Bresick G, Sayed A-R, Le Grange C, et al. Adaptation and cross-cultural validationof the United States primary care assessment tool (expanded version) for use in South Africa. African J Prim Heal Care Fam Med. 2015;7:1-11.

14. Shi $\mathrm{L}$, Starfield B, Xu J. Validating the adult primary care assessment tool. J Fam Pr. 2001;50:161-175. 
15. D'Avila OP, Pinto LdS, Hauser L, et al. O uso do primary care assessment tool (PCAT): uma revisão integrativa e proposta de atualização. Cien Saude Colet. 2017;22:855-865.

16. Dullie L, Meland E, Hetlevik $\varnothing$, et al. Development and validation of a Malawian version of the primary care assessment tool. BMC Fam Pract. 2018;19:63-74.

17. Mukiapini S, Bresick G, Sayed A-R, et al. Baseline measures of primary health care team functioning and overall primary health care performance at Du Noon community health centre. Afr J Prim Heal Care Fam Med. 2018;10:e1-11.

18. Bresick GF, Sayed A-R, Le Grange C, et al. Western Cape primary care assessment tool (PCAT) study: Measuring primary care organisation and performance in the Western Cape province, South Africa. African J Prim Heal Care Fam Med 2016. 2013;8:1-12.

19. von Pressentin KB, Mash RJ, Baldwin-Ragaven $L$, et al. The influence of family physicians within the South African district health system: A cross-sectional study. Ann Fam Med. 2018;16:28-36. DOI:10.1370/ afm.2133.

20. Mash R, Ogunbanjo G, Naidoo SS, et al. The contribution of family physicians to district health services: A national position paper for South Africa. South African Fam Pract. 2015;57:54-61.

21. The Johns Hopkins Primary Care Policy Center - PCA Tools. [cited 2018 Dec 19] https://www.jhsph.edu/research/centers-and-institut es/johns-hopkins-primary-care-policy-center/pca_tools.html.
22. Nxumalo N, Alaba O, Harris B, et al. Utilization of traditional healers in South Africa and costs to patients: findings from a national household survey. J Public Health Policy. 2011;32:S124-S136.

23. Becker J, Dell A, Jenkins L, et al. Reasons why patients with primary health care problems access a secondary hospital emergency centre. South African Med J. 2012;102:800-801.

24. Gray DJP, Sidaway-Lee K, White E, et al. Continuity of care with doctors - a matter of life and death? A systematic review of continuity of care and mortality. BMJ Open. 2018;8:e021161.

25. Alazri M, Heywood P, Neal RD, et al. Continuity of care: literature review and implications. Sultan Qaboos Univ Med J. 2007;7:197-206.

26. van Servellen G, Fongwa M, Mockus D'Errico E. Continuity of care and quality care outcomes for people experiencing chronic conditions: A literature review. Nurs Health Sci. 2006;8:185-195.

27. Burge F, Haggerty JL, Pineault R, et al. Relational continuity from the patient perspective: comparison of primary healthcare evaluation instruments. Healthc Policy. 2011;7:124-138.

28. Bam N, Marcus T, Hugo J, et al. Conceptualizing community Oriented primary care (COPC)-the Tshwane, South Africa, health post model. African J Prim Heal Care Fam Med. 2013;5:a423, doi:10.4102/phcfm. v5i1.423.

29. Marcus T. A practical guide to doing community oriented primary care. Pretoria: Minuteman Press, 2015.

Received: 25-01-2019 Accepted: 15-03-2019 